\title{
Postoral glucose stimulation of intake and conditioned flavor preference in C57BL/6J mice: A concentration-response study
}

\author{
Steven Zukerman ${ }^{\mathrm{a}, \mathrm{b}}$, Karen Ackroffa,b, and Anthony Sclafani ${ }^{\mathrm{a}, \mathrm{b},{ }^{*}}$ \\ aDepartment of Psychology, Brooklyn College, City University of New York, Brooklyn, NY 11210 \\ ${ }^{b}$ Cognition, Brain, and Behavior Doctoral Subprogram, The Graduate School, City University of \\ New York, New York, NY 10016, USA
}

\section{Abstract}

In a recent study, intragastric (IG) self-infusion of $16 \%$ glucose stimulated 1-h intake and conditioned a preference for a flavored saccharin solution in C57BL/6J mice (Zukerman et al., 2011). Experiment 1 of the present study presents a concentration-response analysis of IG glucose-induced intake stimulation monitored by recording licking response every min of the $1 \mathrm{~h} /$ day sessions. Separate groups of food-restricted mice consumed a flavored saccharin solution (the CS-) paired with IG self-infusions of water (Test 0 ) followed by a different flavored solution (the $\mathrm{CS}+$ ) paired with IG self-infusions of 2, 4, 8, 16, or 32\% glucose (Tests 1-3). Following additional CS- and CS+ training sessions, a two-bottle CS+ vs. CS- choice test was conducted without infusions. Self-infusions of $8 \%, 16 \%$ or 32\% glucose stimulated CS+ licking within 12 min of the first test session and even earlier in subsequent test sessions, and also conditioned significant CS+ preferences in the two-bottle test. The stimulation of early licking and CS+ preference increased as a function of glucose concentration. The amount of glucose solute self-infused increased with sugar concentration as did post-infusion blood glucose levels. The $2 \%$ glucose infusion did not stimulate CS+ intake and the $2 \%$ and $4 \%$ infusions failed to produce a CS+ preference in the 1-h test. Experiment 2 revealed that intraperitoneal self-infusions of $8 \%$ glucose, unlike IG glucose self-infusions, failed to stimulate CS+ licking or preference despite producing maximal increases in blood glucose levels. Taken together, these and other findings suggest that glucose rapidly produces concentration-dependent intestinal signals that stimulate intake and condition flavor preferences while postoral satiation signals limit total amounts consumed.

\section{Keywords}

Postoral sugar conditioning; intragastric; intraperitoneal; appetition

\section{Introduction}

In addition to its sweet taste, the postoral actions of sugar contribute to the appetite promoting effects of high-sugar foods and drinks. This has been demonstrated using a variety of experimental procedures and species $[14,43,56]$. The most extensive evidence that

\footnotetext{
(c) 2012 Elsevier Inc. All rights reserved.

*Corresponding author at: Department of Psychology, Brooklyn College of CUNY, 2900 Bedford Avenue, Brooklyn, NY 11210, USA. Tel.: +1-718-951-5606; fax: +1-718-951- 4824. asclafani@gc.cuny.edu (A. Sclafani).

Publisher's Disclaimer: This is a PDF file of an unedited manuscript that has been accepted for publication. As a service to our customers we are providing this early version of the manuscript. The manuscript will undergo copyediting, typesetting, and review of the resulting proof before it is published in its final citable form. Please note that during the production process errors may be discovered which could affect the content, and all legal disclaimers that apply to the journal pertain.
} 
the postoral actions of sugar can stimulate intake and promote flavor preferences is provided by intragastric (IG) infusion experiments conducted with rats and mice [39,44]. For example, in one study C57BL/6J (B6) mice were given 24-h ad libitum chow and access to a flavored non-nutritive solution (the CS+, e.g., grape) paired with IG self-infusion of a matched volume of $16 \%$ sucrose on some days and a different flavored solution (the CS-, e.g., cherry) paired with IG water self-infusions on alternate days [48]. The mice consumed more of the CS+ than CS- during one-bottle training and significantly preferred the CS+ to the CS- in a subsequent two-bottle choice test. These effects were more pronounced with saccharin-sweetened CS solutions than with unsweetened CS solutions, which indicates that sweet taste enhances postoral sugar conditioning [48]. Sucrose is digested to glucose and fructose and a recent report indicates that the glucose moiety is primarily responsible for sucrose conditioning in B6 mice [43]. That is, IG infusions of 16\% glucose stimulated 24-h intake and conditioned a CS+ preference in $\mathrm{B} 6$ mice whereas 16\% fructose infusions failed to do so [43].

The potency of postoral glucose to stimulate intake was further documented in a recent study in which food-restricted B6 mice were trained to drink CS- and CS+ flavored saccharin solutions $1 \mathrm{~h} /$ day while their licking response was evaluated every min [58]. The mice were first trained to drink the CS- solution paired with an IG water self-infusion for three sessions before being tested with the CS+ solution paired with IG self-infusion of $16 \%$ glucose for three sessions. The glucose self-infusion increased licking of the CS+ solution within $15 \mathrm{~min}$ in the first test and total 1-h licks were elevated by $44 \%$ compared to the prior CS- sessions. In the next two CS+ tests, CS+ licking was substantially elevated from the first min of the sessions and total $1 \mathrm{~h}$ licks (and solution intakes) were elevated by $90 \%$ relative to the CS- tests. The mice also significantly preferred the CS+ to the CS- in a subsequent two-bottle choice test conducted without IG infusions. These findings revealed for the first time that postoral sugar infusions can increase ongoing feeding within the first ingestion bout, as well as increasing subsequent bouts and 24-h intakes as previously reported $[43,46,47,48]$.

We proposed the term "appetition" to refer to the process by which postoral nutrients stimulate intake and condition preferences to distinguish it from the satiation process that suppresses intake (Sclafani, 2012). In the present study we conducted a concentrationresponse analysis of postoral appetition by measuring the ingestive responses of B6 mice to IG self-infusions of $2 \%$ to $32 \%$ glucose. Our previous mouse study investigated intake stimulation and preference conditioning using IG infusion of only one concentratiion, $16 \%$ glucose [58]. In rats, IG preference conditioning has been studied using a wide range of IG sugar concentrations $(0.5-32 \%)[1,4,22,34]$ but these studies did not reveal rapid stimulation of intake as observed in mouse [58]. It is well documented that postoral sugar infusions produce a concentration-dependent suppression of eating (satiation) [10,23,25,32,33,57]. Experiment 1 determined how sugar concentration influences the stimulation of intake when mice are offered a novel flavored saccharin solution paired with IG glucose self-infusion.

A second aim of this study was to address the site of action for postoral glucose appetition in B6 mice. Glucose consumed by mouth or infused into the gut can rapidly stimulate pre- and post-absorptive sugar sensors [44]. Prior work in our lab indicated that the upper intestinal tract was a critical site of action for glucose conditioning of flavor preferences. That is, preferences for flavored saccharin solutions were conditioned by glucose infusions into the stomach, duodenum and jejunum, but not by infusions into a stomach with a closed pylorus, or into the ileum or hepatic-portal (HP) vein $[2,16]$. Other investigators, however, reported that HP glucose infusions conditioned a preference for a flavored chow in hungry rats [53] or a water sipper tube side in thirsty rats [29]. Together, these findings suggest a role for both pre- and post-absorptive sites of action for glucose conditioning. In the present study, 
the intake stimulating and preference conditioning effects of IG and intraperitoneal (IP) glucose self-infusions were compared. The IP route was selected because of the difficulty of maintaining a HP catheter in mice and because IP glucose infusions are thought to be absorbed primarily in the hepatic-portal venous system [24,37]. The IP route has also been used to study the satiating and place conditioning effects of glucose $[3,6,7]$. At the end of behavioral testing, the effects of the IG and IP glucose infusions on blood glucose levels were measured to determine the relationship, if any, between the magnitude of the CS+ conditioning response and elevation in blood glucose.

\section{Experiment 1}

This experiment investigated the postoral appetition effects of IG self-infusions of $2 \%$ to $32 \%$ glucose in B6 mice. The training protocol was similar to that in our recent study involving $16 \%$ glucose [58] in that the mice were given three 1-h sessions with the CSpaired with IG water self-infusions and then three sessions with the CS+ paired with IG glucose self-infusions. The mice were subsequently given two-bottle sessions with the CS+ vs. CS- without IG infusions. In the present study the protocol was changed in two ways. First, the concentration of the CS flavors (ethyl acetate or propyl acetate) was increased from 0.01 to $0.02 \%$. Second, after the two blocks of CS- and CS+ training, the mice were given four alternating 1-h sessions with the CS- and CS+ (see [36]). These changes were designed to enhance the ability of the mice to discriminate between the CS- and CS+ flavors in the two-bottle test sessions. As in our prior study, the CS flavors were added to a dilute $(0.025 \%, 1.2 \mathrm{mM})$ saccharin solution that is preferred to water, but minimally stimulates intake in B6 mice [5,40]. This saccharin concentration was selected to keep initial CS intakes relatively low to permit stimulation of intake by IG nutrient self-infusions.

\subsection{Methods}

2.1.1. Subjects-Adult male B6 mice ( $10 \mathrm{wk}$ old) bred in the laboratory from Jackson Laboratories (Bar Harbor, ME) stock were singly housed in plastic tub cages kept in a test room maintained at $22^{\circ} \mathrm{C}$ with a $12: 12$-h light-dark cycle. The mice were maintained on chow (5001; PMI Nutrition International, Brentwood, MO) prior to food restriction. During testing they were fed fixed-size chow pellets ( 0.5 or $1 \mathrm{~g}$, Bio-Serv, Frenchtown, NJ), which allowed for precise adjustment of daily food rations. Experimental protocols were approved by the Institutional Animal Care and Use Committee at Brooklyn College and were performed in accordance with the National Institutes of Health Guidelines for the Care and Use of Laboratory Animals.

2.1.2. Surgery-Mice were fitted with IG catheters $(0.84 \mathrm{~mm}$ OD $\times 0.36 \mathrm{~mm}$ ID, MicroRenathane tubing, MRE-033, Braintree Scientific, Braintree, MA) while anesthetized with isoflurane (2\%) inhalation as previously described [46]. About 10 days after surgery the mice were briefly ( $5 \mathrm{~min}$ ) anesthetized with isoflurane, and tubing was attached to the gastric catheter and then passed through an infusion harness with a spring tether (CIH62, Instech Laboratories, Plymouth Meeting, PA). The tubing was then attached to an infusion swivel mounted on a counterbalanced lever (Instech Laboratories). The body weight of each mouse was measured before and after it was fitted with the infusion tether/swivel system; daily body weights were monitored by weighing the mouse with the attached infusion tether/ swivel system. Each animal was then returned to a tub cage and the swivel counterbalanced lever was attached above the cage.

2.1.3. Apparatus-IG infusion tests were conducted in plastic test cages [46]. The sipper spouts were interfaced via electronic lickometers (Med Electronics, St. Albans, VT) to a computer, which operated a syringe pump (A-99; Razel Scientific, Stamford, CT) that 
infused liquid into the gastric catheters as the animals licked. The pump rate was nominally $0.5 \mathrm{ml} / \mathrm{min}$, but the animal controlled the overall infusion rate and volume by its licking response. In particular, the computer accumulated licks during 3-sec bins and activated the pump for $3 \mathrm{sec}$ when a criterion number of licks was recorded. The oral-to-infusion intake ratio was maintained at $\sim 1: 1$ by adjusting the lick criterion for each mouse. Daily oral fluid intakes were measured to the nearest $0.1 \mathrm{~g}$, and IG infusions were recorded to the nearest 0.5 $\mathrm{ml}$.

2.1.4. Test solutions-The CS solutions contained $0.025 \%$ sodium saccharin (Sigma Chemical Co., St. Louis, MO) flavored with $0.02 \%$ ethyl acetate or propyl acetate (Sigma). The CS- solution was paired with IG infusion of water while the CS+ solution was paired with IG infusion of food-grade glucose (Honeyville Food Products, Rancho Cucamonga, CA). Separate groups of mice were infused with $2 \%(n=11), 4 \%(n=12), 8 \%(n=10), 16 \%$ $(n=9)$ or $32 \%(n=15)$ glucose. For about half the animals in each group the CS- solution contained ethyl acetate and the CS+ solution contained propyl acetate; the flavors were reversed for the remaining animals.

2.1.5. Procedure-The mice were trained $(1 \mathrm{~h} /$ day $)$ in the test cages for two sessions with unflavored $0.025 \%$ sodium saccharin solution while water deprived and then for four sessions while food-restricted to $85-90 \%$ of their ad libitum body weight; saccharin intakes were paired with matched volume infusions of water. The mice were then given three 1-h test sessions with a CS- saccharin solution paired with IG water infusions followed by three sessions with the CS+ saccharin solution paired with IG infusions of the appropriate glucose concentration. The mice were then given four alternating (A) sessions with the CS-, CS+, $\mathrm{CS}-$ and $\mathrm{CS}+$, in that order, with each solution paired with its respective infusion (IG water or IG glucose). In the final CS- and CS+ sessions the mice were given a second sipper tube containing water not paired with IG infusions to familiarize them to the presence of two sipper tubes in the subsequent two-bottle test. The two-bottle test with the CS+ and CSsolutions no longer paired with IG infusions was conducted over four $1 \mathrm{~h} /$ day sessions.

One or two days following the last two-bottle session, blood glucose levels were measured. Each mouse was infused with $0.6 \mathrm{ml}$ of its respective glucose solution over a 10-minute period. Tail blood samples were measured using a FreeStyle Freedom Lite (Abbott Diabetes Care Inc., Alameda, CA) blood glucose meter just before (0 min), and 15, 30 and $60 \mathrm{~min}$ following the start of the IG infusion. Data were collected from an additional group of mice $(\mathrm{n}=12)$ that were infused IG with $0.6 \mathrm{ml}$ of water instead of glucose. The $0.6 \mathrm{ml}$ infusion volume matched the volume of glucose solution self-infused by the $8 \%$ and $16 \%$ glucose groups during the first $15 \mathrm{~min}$ of CS+ Test 1 . This volume was infused over $10 \mathrm{~min}$ so that it ended before the $15 \mathrm{~min}$ blood sample time point.

2.1.6. Data Analysis-CS- licks and total intakes (oral + IG infusate) during the last two $1 \mathrm{~h} /$ day sessions were averaged. The data from these two sessions, referred to as Test 0 , and the licks and intakes during the three CS+ sessions (Tests 1-3) were analyzed using a mixed model analysis of variance (ANOVA) with a group factor (IG Glucose Concentration) and repeated measure factor (Tests $0-3$ ). The mean licks of CS- and CS+ during the alternating sessions, referred to as CS-A and CS+A, were compared in a separate ANOVA. Additional analyses are described in the results.

Mean cumulative lick curves were generated for Tests $0-3$, and licking rates were also expressed as licks per 3-min bin for each test. The lick bin data were analyzed separately for each group with repeated measure ANOVA (Test $\times$ Bins) with each sugar test compared to Test 0 . If there was an Test $\times$ Bin interaction, simple main effects tests compared each Test 0 bin with each Test $1-3$ bin. 
The blood glucose data were analyzed using a mixed model ANOVA with a group factor and a repeated measure factor (sample time points). In addition, incremental areas under the curve (IAUC) were calculated and compared across groups with a one-way ANOVA.

\subsection{Results}

Figure 1A shows the total 1-h lick data for CS- Test 0 and CS+ Tests 1-3. Analysis of these data revealed that the groups did not differ in their CS- licks paired with IG water selfinfusions (Test 0 ) but did differ in their CS+ licks paired with IG glucose self-infusions [Tests 1- 3; Group $\times$ Test interaction, $\mathrm{F}(12,156)=4.04, \mathrm{P}<0.001$ ]. Whereas the $4 \%, 8 \%$, $16 \%$ groups significantly $(\mathrm{P}<0.001)$ increased their 1 -h licks when switched from the CSto the $\mathrm{CS}+$, the $32 \%$ group displayed a marginal increase $(\mathrm{P}<0.056)$ and the $2 \%$ group showed no increase. A comparison of the CS+ Tests 1-3 licks indicated that, overall, the $8 \%$ (1342.7) and $16 \%$ (1240.3) groups emitted more ( $\mathrm{P}<0.05)$ licks than did the $2 \%(821.6)$, $4 \%(970.0)$, and $32 \%(934.9)$ groups $[\mathrm{F}(4,52)=8.42, \mathrm{P}<0.001]$. Within group analyses revealed that the $4 \%$ group licked more in CS+ Test 2 than Tests 0 and 1 ; the $8 \%$ group licked more in Tests 1-3 than Test 0 ; the 16\% group licked more in CS+ Tests 1-3 than in CS- Test 0 and more in CS+ Test 3 than Test 1 . The 1-h total intake data (CS solution + IG infusion $\mathrm{g} / \mathrm{h}$ ) revealed a similar pattern of results [Group $\times$ Test interaction, $\mathrm{F}(12,156)=$ $5.38, \mathrm{P}<0.001]$. The $2 \%$ group did not significantly increase their intakes $(\mathrm{g} / \mathrm{h})$ from CSTest 0 to CS+ Tests $1-3(1.9$ to 1.9$)$ whereas significant $(\mathrm{P}<0.01)$ increases were observed with the $4 \%$ (1.9 to 2.2 ), $8 \%$ (2.0 to 3.2 ), and $16 \%$ (1.7 to 2.9 ) groups and a marginal increase ( $\mathrm{P}<0.08)$ with the $32 \%$ group (1.9 to 2.2). The CS- intakes of the groups did not differ in Test 0 , whereas their CS+ intakes in Tests 1-3 statistically differed as follows: $8 \%$ $\geq 16 \%>4 \% \geq 32 \% \geq 2 \%$. However, when intakes in CS+ Tests $1-3$ were expressed as glucose solute infused $(\mathrm{g} / \mathrm{h})$, the group intake pattern was quite different: $32 \%(0.46 \mathrm{~g})>$ $16 \%(0.28)>8 \%(0.14)>4 \%(0.05 \mathrm{~g}) \geq 2 \%(0.02)[\mathrm{F}(4,52)=203.2, \mathrm{P}<0.001]$.

In the alternating sessions, the groups differed in their CS+ and CS- licks [Group $\times \mathrm{CS}$ interaction, $\mathrm{F}(4,52)=23.12, \mathrm{P}<0.001$ ] (Figure $2 \mathrm{~A}$ ). In this case, the $4 \%$ and $8 \%$ groups licked more $(\mathrm{P}<0.05)$ for the CS+ than CS-, the $2 \%$ and $16 \%$ groups did not lick more for the CS+ than CS-, while the $32 \%$ group licked less $(\mathrm{P}<0.05)$ for the CS+ than CS-. A comparison of the CS- licks during the alternating (Test R) and Test 0 sessions, which occurred after and before CS+ testing respectively, also revealed significant group differences [Group $\times$ Test interaction $(F(4,52)=7.23, \mathrm{P}<0.001$ ] (Figure 2B). In particular, the $8 \%, 16 \%$, and $32 \%$ groups significantly $(\mathrm{P}<0.01)$ increased their CS-licking from Test 0 to Test $\mathrm{A}$ whereas the $2 \%$ and $4 \%$ groups differ in Test 0 and $\mathrm{A}$ licks (Figure 2B). The increased CS- licks in Test A (post-CS+ training) of the 8\%, 16\%, and 32\% groups may represent a generalization of their increased attraction for the CS+ flavor to that of the CSflavor (see Discussion).

Figure 1B presents the mean lick data for the four two-bottle CS+ vs. CS- choice tests conducted without IG infusions. Analysis of these data revealed a Group $\times$ CS interaction $[\mathrm{F}(4,52)=39.41, \mathrm{P}<0.001]$. In particular, the $8 \%, 16 \%$, and $32 \%$ groups licked significantly more $(\mathrm{P}<0.001)$ for the CS+ than CS-, while the CS intakes of the $2 \%$ and $4 \%$ groups did not differ. Furthermore, $\mathrm{CS}+$ licks increased $(\mathrm{P}<0.001)$ with concentration from $2 \%$ and $4 \%$ to $8 \%, 16 \%$, and $32 \%$, while CS- licks decreased $(\mathrm{P}<0.001)$ with concentration. Similar results were obtained in the analysis of CS+ and CS- intakes during the two-bottle tests (data not shown). The groups also differed in their percent CS+ licks $[\mathrm{F}(4,52)=51.16, \mathrm{P}<0.001]$ and the $32 \%$ group displayed the highest preference $(91 \%)$ followed by the $16 \%(80 \%)$ and $8 \%(70 \%)$ groups and then $4 \%$ and $2 \%$ groups at $52 \%$ each. Note that percent CS+ licks of the 8,16 and $32 \%$ groups did not change over the four test sessions even though the mice were no longer infused with IG glucose, i.e., there was no extinction of the CS+ preference (see Supplementary Figure 1). 
Figures 3 present the CS- and CS+ licks data from Tests 0 to 3 expressed as licks $/ 3$ min and cumulative lick curves. Statistical analysis was performed on the 3 min data and the cumulative lick curves are included to show the evolution of the licking response during the 1-h sessions. For the $2 \%$ group, 3-min licks did not significantly change from Tests 0 to 3 but, overall, licks rates gradually declined during the 1-h sessions $[\mathrm{F}(19,190)=7.95, \mathrm{P}<$ 0.001]. In CS- Test 0 the average lick rates in successive quarters of the 1-h session declined from $46.6,43.0,34.5$ to 22.6 licks/3 min which was characteristic of the Test 0 lick rates of the remaining groups. The $4 \%$ group licked more per 3-min bin in CS+ Test 2 than in CS- Test 0 and CS+ Test $1[\mathrm{~F}(3,33)=3.70, \mathrm{P}<0.05]$. Analysis of the Test 0 and 2 data indicated that the $4 \%$ group licked more $(\mathrm{P}<0.05) \mathrm{CS}+$ than CS- in bin 5; no other differences were significant (Test $\times$ Bin interaction, $\mathrm{F}(57,627)=1.56, \mathrm{P}<0.001)$. The mice in the 8\% group licked more per $3 \mathrm{~min}$ in Tests $1-3$ than in CS- Test $0[\mathrm{~F}(3,33)=14.98, \mathrm{P}$ $<0.001]$. Compared to the CS- test, the $8 \%$ group licked more $(\mathrm{P}<0.05) \mathrm{CS}+$ in bins 3 to $11,2-8$, and $1-7$ in Tests 1 to 3, respectively (Test $\times$ Bin interaction, $\mathrm{F}(57,798)=5.74, \mathrm{P}<$ $0.001)$. For the $16 \%$ group, licks per 3 -min bin in Tests $1-3$ exceeded $(\mathrm{P}<0.01) \mathrm{CS}-$ licks in Test 0 , and CS+ licks in Test 3 exceeded those in Test $1[\mathrm{~F}(3,24)=12.14, \mathrm{P}<0.001]$. Compared to Test 0 , the $16 \%$ group licked more $(\mathrm{P}<0.05)$ for $\mathrm{CS}+$ in bins $2-8,2-5$, and $1-$ 5 in Tests $1-3$ respectively (Test $\times$ Bin interaction, $F(57,456)=3.01, \mathrm{P}<0.001)$. The $32 \%$ group displayed significant changes in licks per 3-min bin from Tests 0 to $3[F(3,42)=3.94$, $\mathrm{P}<0.05]$. Compared to CS- licks in Test 0 , the $32 \%$ mice licked more CS+ in bins 4-8, 14, and 1-3 in Tests 1 to 3, respectively (Test $\times$ Bin interaction, $\mathrm{F}(57,798)=18.94, \mathrm{P}<$ $0.001)$. Note that in Test 1 the $16 \%$ group showed an earlier significant increase in CS+ licking (bin 2) compared to the $8 \%$ (bin 3) and $32 \%$ (bin 4) groups. This may be related, in part, to the spontaneous (and unexplained) drop in CS- licks displayed by the 16\% group in bins $2-3$. In the $8 \%, 16 \%$, and $32 \%$ groups CS+ lick rates rapidly declined after reaching their peaks 1-7 min into the sessions as the mice presumably experienced the satiating actions of the infused glucose.

A between-group analysis was performed on the 3-min licks of the five IG glucose groups. This analysis was limited to the first 3-min (bin 1) based on prior data showing that initial lick rates reflect the attractiveness (palatability) of a taste solution independent of postoral satiation effects $[12,19,45]$. As illustrated in Figure 4, the groups significantly differed in their initial 3-min licks as a function of the CS tests [Group $\times$ Test interaction, $\mathrm{F}(4,52)=$ $16.68, \mathrm{P}<0.001]$. In particular, whereas 3 -min licks did not significantly increase from Test 0 to 3 in the $2 \%, 4 \%$, and $8 \%$ groups, significant differences appeared in the $16 \%$ and $32 \%$ groups. In particular, the $16 \%$ group licked more for the CS+ in Test 3 than for CS- in Test 0 and CS+ in Test 1 . They also licked more in Test 3 than did the $2 \%$ group. The $32 \%$ mice displayed even greater changes: they licked more in Test 2 than in Tests 0 and 1 , and more in Test 3 than in Tests 0-2. In addition, they licked more in Test 3 than did all other groups. Note that in this analysis the increase in licks from Tests 0 to 3 was not significant in the $8 \%$ group, although it was significant in the bin analysis presented in Figure 3.

Figure 5 presents the blood glucose (BG) data following IG infusions of $0 \%$ to $32 \%$ glucose in the different groups (data were lost from two mice in the $2 \%$ group). Analysis of the absolute BG data (Figure 5A) revealed that overall the 0\%-32\% groups differed in the BG response $[F(5,61)=43.9, \mathrm{P}<0.001]$ and the effect varied as a function of time point [Group $\times$ Time interaction, $\mathrm{F}(15,183)=44.6, \mathrm{P}<0.001]$. The groups did not differ at the 0 and 60 min time points; at the 15 and 30 min points they differed $(\mathrm{P}<0.05)$ as follows: $16 \%>32 \%$ $>8 \%>4 \%>2 \%=0 \%$, and $32 \%>16 \%>8 \%=4 \%=2 \%=0 \%$. Analysis of IAUC data (Figure 5B) also revealed the following group differences: $32 \%>16 \%>8 \% \geq 4 \%=2 \%=$ $0 \% ; 8 \%>0 \%[\mathrm{~F}(5,61) 45.14, \mathrm{P}<0.0001]$. 


\section{Experiment 2}

In the first experiment IG self-infusions of 8 to $32 \%$ glucose stimulated CS+ intake and conditioned significant CS+ preferences. The IG glucose infusions also produced concentration-dependent increases in blood glucose but these data do not show whether the glucose was acting at a pre-absorptive or post-absorptive site to stimulate intake and preference. The prior literature on this issue is mixed, with some studies reporting that HP glucose infusions failed to condition preferences for flavored saccharin solutions $[2,20]$, whereas others indicate that HP or IV infusions conditioned preferences for flavored chow or sipper tube preferences [29,53]. In Experiment 2 we determined if IP self-infusions of glucose stimulate CS+ intake and preference in a manner similar to that observed with IG glucose infusions. An $8 \%$ glucose infusion was used because it is a near-isotonic concentration, was effective when delivered by the IG route, and produces elevations in plasma glucose within the range observed with the IG infusions of the first experiment.

\subsection{Method}

A modified procedure was used in this experiment because IP catheters remain patent for a shorter time than do IG catheters. The B6 mice $(\mathrm{n}=12)$ were first fitted with the infusion harness and tether and trained to drink unflavored saccharin in the test cages for seven $1 \mathrm{hr} /$ day sessions as in Experiment 1. They were fitted with an IP catheter under isoflurane (2\%) anesthesia. The catheter (MRE-33, Micro-Renathane tubing) was placed in the peritoneal cavity and anchored with dacron mesh to the inside of the abdominal muscle. The distal end passed through an incision in the abdominal muscle, was routed under the skin to the back of the neck, and passed through a hole in the skin to an infusion harness and spring tether (Instech Laboratories). Two days later, the mice were given two $1 \mathrm{~h} /$ day sessions with the unflavored saccharin paired with IP self-infusions of sterile isotonic saline using the same infusion parameters as in first experiment. The mice were then given a sequence of onebottle and two-bottle tests with the CS- and CS+ as in the first experiment, except that the CS- was paired with IP self-infusions of sterile saline, and the CS+ with self-infusions of sterile $8 \%$ glucose during the 1-bottle sessions. A blood glucose test was conducted the day after the final two-bottle test during which the mice were infused IP with $0.6 \mathrm{ml}$ of $8 \%$ glucose as tail blood samples were analyzed as in Experiment 1. Two days later, a postmortem examination with an infused dye confirmed that all catheters were patent.

The lick, intake, and blood glucose data from the IP group was compared to that of the IG 8\% glucose group from Experiment 1 in separate ANOVAs.

\subsection{Results}

Figure 6 presents the total 1-h lick data for Tests $0-3$ of the IP and IG $8 \%$ glucose groups. Analysis of these data revealed that the groups did not differ in their CS- licks (Test 0 ) but did differ in their CS+ licks paired with IG glucose self-infusions [Test $\times$ Group Interaction, $\mathrm{F}(3,60)=11.65, \mathrm{P}<0.001]$. The IP group showed no change in total 1 -h licks when switched from the CS- in Test 0 to the CS+ in Tests 1-3 whereas the IG group significantly increased $(\mathrm{P}<0.01)$ its total licks in Tests $1-3$. The IP glucose group also showed no changes in lick/3-min bin curves from Test 0 to Tests $1-3$ although, overall, licks rates gradually declined during the 1 -h sessions $[\mathrm{F}(19,209)=8.15$, P $<0.001]$. (Figure 3F).This is in marked contrast to the substantial increases in licks $/ 3 \mathrm{~min}$ bins displayed by the IG glucose group as described in Experiment 1 (see Figure 3C). Consistent with the lick data, total solution intake (oral CS + IP infusion) did not change in the IP group from Test 0 (1.6 $\mathrm{g} / \mathrm{h})$ to Tests $1-3(1.6 \mathrm{~g} / \mathrm{h})$ whereas the IG $8 \%$ group increased its total intake from Test 0 to $1-3(2.0$ to $3.2 \mathrm{~g} / \mathrm{h})$ [Test $\times$ Group Interaction, $\mathrm{F}(3,60)=11.65, \mathrm{P}<0.001]$. The groups also differed in their CS licks in the two-bottle choice test $(\mathrm{CS} \times$ Group interaction, $\mathrm{F}(1,32)=$ 
32.7, $\mathrm{P}<0.001)$. The IP group licked significantly less $(\mathrm{P}<0.01)$ for the $\mathrm{CS}+$ than for the $\mathrm{CS}-$, and their CS+ preferences was 43\% (Figure 6) whereas the IG group licked more for the CS+ and had a 70\% CS+ preference. The low CS+ preference (i.e., mild avoidance) displayed by the IP mice in the two-bottle test suggests that the IP glucose infusion had some negative visceral consequence. Yet, statistical analysis revealed a positive correlation $\left(\mathrm{r}^{2}=0.71, \mathrm{P}<0.01\right)$ between the mean intake (oral $\left.+\mathrm{IP}\right)$ during training CS+ sessions and the mean percent CS+ preference in the two-bottle sessions (see Supplementary Figure 2). The mice that infused the most glucose IP were indifferent to the CS+ whereas the mice that infused the least glucose showed a reduced CS+ preference.

Although the difference was not significant, the IP glucose group emitted fewer licks in Test 0 than did the IG glucose group (Figure 6). It is possible that because of their low CSbaseline licking rate in Test 0 , the IP mice did not self-infuse enough glucose in Tests $1-3$ to stimulate CS+ intake and preference. This interpretation is not supported, however, by an analysis of selected IP and IG mice ( $\mathrm{n}=7$ each) that had near-identical CS- licks (760.1 vs. 761.0) and intakes ( 1.93 vs. $1.85 \mathrm{~g}$ ) in Test 0 . The selected IP mice failed to increase their licks and intakes in CS+ Tests 1-3 and did not differ in their two-bottle CS+ and CS- licks (379.2 vs. 434.1 licks $/ \mathrm{h}, 46 \% \mathrm{CS}+$ preference). In contrast, the selected IG mice increased their CS+ intakes in Tests 1-3 and displayed a CS+ preference (69\%) similar to those of the entire IG group.

Although the IP and IG $8 \%$ groups were infused with identical amounts of sugar in the glucose tolerance test, the IP mice displayed higher $(\mathrm{P}<0.01)$ blood glucose values at the 15,30 and $60 \mathrm{~min}$ time points than did the IG $8 \%$ glucose group [Group $\times$ Time interaction, $\mathrm{F}(3,60)=69.6, \mathrm{P}<0.001]($ Figure $5 \mathrm{~A})$ and a greater $(\mathrm{P}<0.01)$ IAUC $(\mathrm{t}(20)=10.19, \mathrm{P}<$ 0.001 ; Figure 5B). In contrast, the absolute and IAUC blood glucose values of the IP $8 \%$ group did not significantly differ from that of the $32 \%$ IG glucose group (Figure 5A, B).

\section{Discussion}

The present study confirms and extends our recent finding [58] that IG self-infusion of $16 \%$ glucose rapidly stimulates the licking response to the CS+ flavored saccharin solution in the very first test session. In Experiment 1, the 8\%, 16\% and 32\% IG glucose groups increased their CS+ licking rate by 6 to $12 \mathrm{~min}$ into Test 1 and showed even greater increases in early lick rates in Tests 2 and 3. Lick rates declined later in the 1-h sessions as the mice experienced the satiating actions of the self-infused glucose. These groups also displayed a significant and persistent preference for the CS+ in the two-bottle choice tests conducted without IG infusions. In contrast, the $4 \%$ and $2 \%$ glucose groups showed a smaller or no increase, respectively, in their CS+ licks and both groups failed to prefer the CS+ to CS- in the choice test.

In addition to stimulating licking early in the CS+ sessions, the $8 \%$ and $16 \%$ IG glucose self-infusions significantly increased total 1 -h licks in Tests $1-3$ by $50 \%$ to $100 \%$, compared to CS- Test 0 , while the $32 \%$ glucose infusions only marginally increased total 1 -h licks in Tests $1-3$ (by $27 \%$ to $44 \%$ ). The weak stimulatory effect of the $32 \%$ glucose infusions on total 1-h licks and intakes can be attributed to the satiating action of the concentrated sugar solution. In particular, while the $32 \%$ mice self-infused less glucose solution, they infused significantly more glucose solute than did the $16 \%$ and $8 \%$ mice $(0.46,0.28$, and $0.14 \mathrm{~g} / \mathrm{h}$, respectively) in CS+ Tests 1-3. In contrast to the 1-h lick data, there were concentrationdependent increases in the initial 3-min licks in Tests 1-3 and in the absolute and percent CS + licks in the two-bottle test. A common feature of these response measures is that they were uninfluenced by the postoral satiating actions of the infused glucose. With respect to the 3min lick data, prior studies show that initial lick rates increase monotonically with sugar 
concentration whereas 30- or 60-min sugar intakes increase and then decrease as sugar concentration increases due to the satiating action of concentrated sugar solutions $[12,13,18,45,52]$ which are consistent with the present findings. In the case of the two-bottle data, the mice were not infused IG during the 1-h sessions so that CS+ licks (and intakes) were not constrained by post-oral glucose satiation. Taken together, the 3-min lick and preference results indicate that the glucose infusions produced concentration-dependent conditioned increases in the reward value of the CS+.

Food reward is thought to include separate hedonic (palatability) and incentive (wanting) components, and prior flavor conditioning studies suggest that IG glucose infusions condition increases in both reward components [9]. As in the present study, IG glucose infusions in rats increase initial CS+ lick rates and as well as lick cluster size and positive taste reactivity responses, which are interpreted as evidence for increased taste palatability $[17,26,27,52]$. Note that in the rat studies. glucose infusions did not stimulate intake and licks until after multiple training sessions $[11,30,50]$ in contrast to the intake stimulation observed in the very first session in the present and recent mouse experiments [58]. Different training procedures were used in the rat and mouse experiments and we recently observed rapid IG glucose stimulation of licking in rats trained as in the present study (Sclafani \& Ackroff, unpublished data). IG glucose infusions also increase progressive ratio operant responding for a CS+ solution compared to a CS- solution, which is evidence for a conditioned increase in the incentive value of the CS+ flavor [42].

A novel finding of the present study is that the $8 \%, 16 \%$ and $32 \%$ glucose infusions not only stimulated CS+ licking but also produced concentration-dependent increases in CS- licking in the alternating sessions following Tests $1-3$. The increased CS- licks may represent a generalized increase in the attraction to sweet taste which was common to the CS+ and CSsolutions. In other experiments we have observed that mice trained as in the present experiment with a CS+ paired with self-infusions of 8 or $16 \%$ glucose licked more for unflavored saccharin following training then they did in the pretraining sessions (Sclafani, unpublished findings). Alternatively, IG infusions of $8-32 \%$ glucose may have produced a non-specific activation of licking in the test chambers. Further research is needed to distinguish between these interpretations although some data supports the taste generalization view. In earlier rat studies we observed that IG infusions of Polycose (a glucose polymer) conditioned a robust $\mathrm{CS}+$ preference but also increased the preference for the CS- solution, relative to water, when the CS+ and CS- solutions shared a common taste component (i.e., sour taste) but decreased the preference for the CS- solution (relative to water) when the CS solutions had distinct tastes (i.e., sour vs. bitter) [31,38]. Yet, despite their increased CS- licking in the alternating sessions, the $8 \%, 16 \%$ and $32 \%$ groups clearly distinguished the $\mathrm{CS}-$ from the $\mathrm{CS}+$ as indicated by their significant $\mathrm{CS}+$ preferences in the subsequent two-bottle test.

In contrast to the CS+ preferences displayed by the $8 \%-32 \%$ groups, the $2 \%$ and $4 \%$ groups were indifferent to the CS+ and CS- in the two-choice tests. Yet the $4 \%$ group displayed a small, but significant increase in CS+ licks in Test 2 . Thus, the $4 \%$ glucose infusion was just above threshold to stimulate CS+ intake in the one-bottle tests, but the $2 \%$ and $4 \%$ infusions were below threshold to condition a two-bottle preference. To determine if more prolonged experience with glucose self-infusions would condition a CS+ preference, the $2 \%$ and $4 \%$ mice were given additional training following the end of Experiment 1 . That is, they were given four alternating $20 \mathrm{~h}$ /day 1-bottle sessions with the CS+ and CS- followed by $20 \mathrm{~h} /$ day two-bottle tests. The $4 \%$ mice licked more for the CS+ than CS- in the one-bottle sessions and also preferred (68-71\%) the CS+ in reinforced (with glucose infusions) and non-reinforced (no glucose infusions) two-bottle tests (Supplementary Figure 3). The 2\% group also licked more for the CS+ in the one-bottle sessions but did not prefer the CS+ in 
the two-bottle tests (Supplementary Figure 3). Thus, with extended training $4 \%$ but not $2 \%$ glucose infusions conditioned flavor preferences in the mice. These results differ from those of a prior study in which rats displayed preferences for a CS+ that was paired with IG selfinfusions of $1 \%, 2 \%$, or $4 \%$ Polycose [1]. Procedural differences, in addition to the different carbohydrates used (glucose vs. Polycose) may account for the discrepant findings. In particular, the rats were trained with more distinctive CS solutions (bitter-sweet vs. soursweet) and were given more extensive one-bottle training (20 days) than the mice in the present study. Thus, it is possible that with more extended training, concentrations lower than $4 \%$ would condition a CS+ preference in mice. In any event, the current 20-h preference data indicate that B6 mice are responsive to the postoral actions of glucose solutions as dilute as $2 \%$ (since the $4 \%$ glucose infusion was diluted to $2 \%$ by the orally consumed CS+ solution). This may be related to our observation that naïve $\mathrm{B} 6$ mice given 48-h oral glucose vs. water preference tests with ascending sugar concentrations of 0.5 $32 \%$, first significantly preferred glucose to water at the $2 \%$ concentration (Zukerman et al., in preparation). After completing the test series, the mice preferred all glucose concentrations by $90 \%$ or more in a retest, which is consistent with the present findings that postoral glucose enhances the preference for minimally sweet solutions.

Blood glucose measures revealed, as expected, that the IG glucose infusions produced concentration-dependent increases in blood glucose. Furthermore, these changes were apparent at a post-infusion time point $(15 \mathrm{~min})$ during which the $8-32 \%$ glucose selfinfusions stimulated CS+ intakes in Tests $1-3$. These findings raise the possibility that the stimulated intake and preference conditioning produced by IG glucose infusions were mediated by the post-absorptive actions of the sugar. However, the failure of IP selfinfusions of $8 \%$ glucose to stimulate CS+ intake or preference does does not support this interpretation. The IP $8 \%$ glucose increased blood glucose levels much more than did the IG $8 \%$ glucose infusions, in fact to the levels produced by IG $32 \%$ infusions, yet only the IG self-infusions conditioned a CS+ preference. Instead, the IP glucose self-infusions produced a mild CS+ avoidance (43\%) suggesting that they had an aversive consequence. Yet the mice did not decrease their CS+ licking over Tests 1 to 3 and CS+ preference was inversely correlated with the amount of glucose self-infused, responses that are inconsistent with a glucose aversion interpretation. IP glucose is assumed to be absorbed primarily in the HP venous system $[24,37]$ and thus the present findings are consistent with prior observations that that HP glucose infusions, unlike IG or ID infusions, fail to condition preferences for a CS+ flavored saccharin solution [2,16,20]. HP glucose infusions were reported, however, to condition a preference for a flavored chow which itself provided pre- and post-absorptive nutrient stimulation to the rats [53]. More recently, HP and IV glucose infusions conditioned a side preference in thirsty rats drinking water from differently placed sipper tubes [29]. Thus, the significant flavored saccharin preferences conditioned by gastric and intestinal glucose infusions suggests an upper intestine site of action but post-absorptive sites, in particular the hepatic-portal region in rats [29,53], are also implicated in some forms of glucose conditioning.

As discussed in detail elsewhere [2,44], the sensing mechanism by which intestinal glucose stimulates intake and preference is not certain. Several findings, however, argue against the involvement of intestinal T1R2/T1R3 sweet receptors and point instead to a glucose-specific sensor such as SGLT1 and/or SGLT3 [44]. The gut-brain pathway by which intestinal glucose conditions flavor preference is also unclear. A critical role for visceral afferent fibers is discounted by the findings that visceral deafferentation produced by systemic capsaicin treatment, vagotomy, and celiac-superior mesenteric ganglionectomy does not block postoral glucose stimulation of intake and preference [44,58]. Direct gut-brain hormone signaling is an alternate pathway although most gut hormones released by glucose suppress rather than stimulate feeding [44]. It is possible, however, that one or more 
hormones may have biphasic stimulatory and inhibitory actions which have yet to be revealed because typical feeding tests are designed to measure satiation, not appetition $[2,44]$. Alternately, a novel hormone released by intestinal glucose may mediate postoral glucose appetition. The test procedure used in the current study provides an example of a protocol that can reveal both stimulatory and inhibitory actions of a nutrient on intake.

It is well documented that the sweet taste of sugars produce concentration-dependent increases in appetitive and consumatory responses when postoral satiation effects are minimized. In particular, rats and mice show monotonic increases in licking rates in brief access tests, intakes in sham feeding tests, and operant responses in progressive ratio tests as sugar concentration increases $[12,13,18,28,35,41,45,55]$. The present findings revealed for the first time that the postoral actions of glucose produce concentration-dependent increases in consumatory and preference responses when an oral sweet taste stimulus (e.g., $0.025 \%$ saccharin) is held constant. Thus, both the oral and postoral actions of glucose and glucosecontaining carbohydrates (sucrose, maltose, Polycose) contribute to sugar appetite. This can explain why rodents are more attracted to sugars than nonnutritive sweeteners, which do not produce postoral appetition $[8,15,46]$. Recent findings indicate that both the oral taste and postoral nutrient actions of sugars activate the brain dopamine reward system which is one major determinant of food reward $[8,9,15,21,49,51,54]$.

\section{Supplementary Material}

Refer to Web version on PubMed Central for supplementary material.

\section{Acknowledgments}

This research was supported by grant DK-31135 from the National Institute of Diabetes and Digestive and Kidney Diseases. The authors thank Kwame McCartney for his expert technical assistance.

\section{References}

1. Ackroff K, Sclafani A. Flavor preferences conditioned by intragastric infusions of dilute Polycose solutions. Physiol Behav. 1994; 55:957-962. [PubMed: 8022918]

2. Ackroff K, Yiin YM, Sclafani A. Post-oral infusion sites that support glucoseconditioned flavor preferences in rats. Physiol Behav. 2010; 99:402-411. [PubMed: 20026145]

3. Ågmo A, Marroquin E. Role of gustatory and postingestive actions of sweeteners in the generation of positive affect as evaluated by place preference conditioning. Appetite. 1997; 29:269-289. [PubMed: 9468761]

4. Azzara AV, Sclafani A. Flavor preferences conditioned by intragastric sugar infusions in rats: Maltose is more reinforcing than sucrose. Physiol Behav. 1998; 64:535-541. [PubMed: 9761229]

5. Bachmanov AA, Tordoff MG, Beauchamp GK. Sweetener preference of C57BL/6ByJ and 129P3/J mice. Chem Senses. 2001; 26:905-913. [PubMed: 11555485]

6. Becskei C, Lutz TA, Riediger T. Glucose reverses fasting-induced activation in the arcuate nucleus of mice. Neuroreport. 2008; 19:105-109. [PubMed: 18281902]

7. Bédard M, Weingarten HP. Postabsorptive glucose decreases the excitatory effects of taste on ingestion. Am J Physiol. 1989; 256:R1142-R1147. [PubMed: 2719156]

8. Beeler JA, McCutcheon JE, Cao ZF, Murakami M, Alexander E, Roitman MF, Zhuang X. Taste uncoupled from nutrition fails to sustain the reinforcing properties of food. Eur J Neurosci. 2012; 36:2533-2546. [PubMed: 22712685]

9. Berridge KC. 'Liking' and 'wanting' food rewards: Brain substrates and roles in eating disorders. Physiol Behav. 2009; 97:537-550. [PubMed: 19336238]

10. Campbell CS, Davis JD. Peripheral control of food intake: Interaction between test diet and postingestive chemoreception. Physiol Behav. 1974; 12:377-384. [PubMed: 4820134] 
11. Capretta PJ. Saccharin consumption under varied conditions of hunger drive. J Comp Physiol Psychol. 1962; 55:656-660. [PubMed: 13876378]

12. Davis JD. The effectiveness of some sugars in stimulating licking behavior in the rat. Physiol Behav. 1973; 11:39-45. [PubMed: 4732426]

13. Davis JD, Breslin PAS. behavioral analysis of the ingestion of glucose, maltose and maltooligosaccharide by rats. Physiol Behav. 2000; 69:477-485. [PubMed: 10913787]

14. De Araujo IE. Sweet taste signaling and the formation of memories of energy sources. Front Syst Neurosci. 2011; 5

15. De Araujo IE, Oliveira-Maia AJ, Sotnikova TD, Gainetdinov RR, Caron MG, Nicolelis MAL, Simon SA. Food reward in the absence of taste receptor signaling. Neuron. 2008; 57:930-941. [PubMed: 18367093]

16. Drucker DB, Sclafani A. The role of gastric and postgastric sites in glucose-conditioned flavor preferences in rats. Physiol Behav. 1997; 61:351-358. [PubMed: 9035269]

17. Dwyer DM. Licking and liking: The assessment of hedonic responses in rodents. Q J Exp Psychol. 2012; 65:371-394.

18. Glendinning JI, Beltran F, Benton L, Cheng S, Gieseke J, Gillman J, Spain HN. Taste does not determine daily intake of dilute sugar solutions in mice. Am J Physiol Regul Integr Comp Physiol. 2010; 299:R1333-R1341. [PubMed: 20702804]

19. Glendinning JI, Chyou S, Lin I, Onishi M, Patel P, Zheng KH. Initial licking responses of mice to sweeteners: effects of Tas1R3 polymorphisms. Chem Senses. 2005; 30:601-614. [PubMed: 16135742]

20. Gowans, SE. Role of portal and plasma glucose elevations in taste-to-postingestive consequence learning [Doctoral Dissertation]. Hamilton: McMaster University; 1992.

21. Hajnal, A.; Norgren, R. Dopamine release by sucrose. In: Basbaum, AI.; Kaneko, A.; Shepherd, GM.; Westheimer, G.; Albright, TD.; Masland, RH.; Dallos, P.; Oertel, D.; Firestein, S.;

Beauchamp, GK.; Bushnell, MC.; Kaas, JH.; Gardner, E., editors. The Senses: A Comprehensive Reference. New York: Academic Press; 2008. p. 459-468.

22. Lucas F, Azzara AV, Sclafani A. Flavor preferences conditioned by intragastric Polycose in rats: More concentrated Polycose is not always more reinforcing. Physiol Behav. 1998; 63:7-14. [PubMed: 9402608]

23. Lucas F, Sclafani A. Capsaicin attenuates feeding suppression but not reinforcement by intestinal nutrients. Am J Physiol. 1996; 270:R1059-R1064. [PubMed: 8928906]

24. Mamoun AH, Anderstam B, Södersten P, Lindholm B, Bergström J. Influence of peritoneal dialysis solutions with glucose and amino acids on ingestive behavior in rats. Kidney Int. 1996; 49:1276-1282. [PubMed: 8731091]

25. Meyer JH, Hlinka M, Tabrizi Y, Dimaso N, Raybould HE. Chemical specificities and intestinal distributions of nutrient-driven satiety. Am J Physiol. 1998; 275:R1293-R1307. [PubMed: 9756563]

26. Myers KP, Sclafani A. Conditioned enhancement of flavor evaluation reinforced by intragastric glucose: I. Intake acceptance and preference analysis. Physiol Behav. 2001; 74:481-493. [PubMed: 11790408]

27. Myers KP, Sclafani A. Conditioned acceptance and preference but not altered taste reactivity responses to bitter and sour flavors paired with intragastric glucose infusion. Physiol Behav. 2003; 78:173-183. [PubMed: 12576114]

28. Nissenbaum JW, Sclafani A. Sham-feeding response of rats to Polycose and sucrose. Neurosci Biobehav Rev. 1987; 11:215-222. [PubMed: 3614789]

29. Oliveira-Maia AJ, Roberts CD, Walker QD, Luo B, Kuhn C, Simon SA, Nicolelis MA. Intravascular food reward. PLoS One. 2011; 6:e24992. [PubMed: 21980372]

30. Pérez C, Fanizza LJ, Sclafani A. Flavor preferences conditioned by intragastric nutrients in rats fed chow or a cafeteria diet. Appetite. 1999; 32:155-170. [PubMed: 9989925]

31. Pérez C, Lucas F, Sclafani A. Increased flavor preference and acceptance conditioned by the postingestive actions of glucose. Physiol Behav. 1998; 64:483-492. [PubMed: 9761222]

32. Phifer CB, Berthoud H-R. Duodenal nutrient infusions differentially affect sham feeding and Fos expression in rat brain stem. Am J Physiol. 1998; 274:R1725-R1733. [PubMed: 9841547] 
33. Powley TL, Phillips RJ. Gastric satiation is volumetric, intestinal satiation is nutritive. Physiol Behav. 2004; 82:69-74. [PubMed: 15234593]

34. Ramirez I. Intragastric carbohydrate exerts both intake-stimulating and intakesuppressing effects. Behav Neurosci. 1997; 111:612-622. [PubMed: 9189276]

35. Reilly S. Reinforcement value of gustatory stimuli determined by progressive ratio performance. Pharmacol Biochem Behav. 1999; 63:301-311. [PubMed: 10371660]

36. Rodríguez G, Alonso G. Perceptual learning in flavor-aversion learning: Alternating and blocked exposure to a compound of flavors and to an element of that compound. Learn Motiv. 2004; 35:208-220.

37. Rodriguez-Zendejas AM, Vega C, Soto-Mora LM, Russek M. Some effects of intraperitoneal glucose and of intraportal glucose and adrenaline. Physiol Behav. 1968; 3:259-264.

38. Sclafani A. Conditioned food preferences. Bull Psychon Soc. 1991; 29:256-260.

39. Sclafani A. Oral and postoral determinants of food reward. Physiol Behav. 2004; 81:773-779. [PubMed: 15234183]

40. Sclafani A. Enhanced sucrose and Polycose preference in sweet "sensitive" (C57BL/6J) and "subsensitive" (129P3/J) mice after experience with these saccharides. Physiol Behav. 2006; 87:745-756. [PubMed: 16529783]

41. Sclafani A, Ackroff K. Reinforcement value of sucrose measured by progressive ratio operant licking in the rat. Physiol Behav. 2003; 79:663-670. [PubMed: 12954407]

42. Sclafani A, Ackroff K. Nutrient-conditioned flavor preference and incentive value measured by progressive ratio licking in rats. Physiol Behav. 2006; 88:88-94. [PubMed: 16626765]

43. Sclafani A, Ackroff K. Flavor preferences conditioned by intragastric glucose but not fructose or galactose in C57BL/6J mice. Physiol Behav. 2012; 106:457-461. [PubMed: 22445944]

44. Sclafani A, Ackroff K. The role of gut nutrient sensing in stimulating appetite and conditioning food preferences. Am J Physiol Regul Integr Comp Physiol. 2012; 302:R1119-R1133. [PubMed: 22442194]

45. Sclafani A, Clyne AE. Hedonic response of rats to polysaccharide and sugar solutions. Neurosci Biobehav Rev. 1987; 11:173-180. [PubMed: 3614783]

46. Sclafani A, Glass DS, Margolskee RF, Glendinning JI. Gut T1R3 sweet taste receptors do not mediate sucrose-conditioned flavor preferences in mice. Am J Physiol Regul Integr Comp Physiol. 2010; 299:R1643-R1650. [PubMed: 20926763]

47. Sclafani A, Glendinning JI. Flavor preferences conditioned in C57BL/6 mice by intragastric carbohydrate self-infusion. Physiol Behav. 2003; 79:783-788. [PubMed: 12954423]

48. Sclafani A, Glendinning JI. Sugar and fat conditioned flavor preferences in C57BL/6J and 129 mice: Oral and postoral interactions. Am J Physiol Regul Integr Comp Physiol. 2005; 289:R712R720. [PubMed: 15845881]

49. Sclafani A, Touzani K, Bodnar RJ. Dopamine and learned food preferences. Physiol Behav. 2011; 104:64-68. [PubMed: 21549727]

50. Sherman JE, Hicks CF, Rice AG, Rusiniak KW, Garcia J. Preferences and aversions for stimuli paired with ethanol in hungry rats. Anim Learn Behav. 1983; 11:101-106.

51. Smith GP. Accumbens dopamine mediates the rewarding effect of orosensory stimulation by sucrose. Appetite. 2004; 43:11-13. [PubMed: 15262012]

52. Spector AC, Klumpp PA, Kaplan JM. Analytical issues in the evaluation of food deprivation and sucrose concentration effects on the microstructure of licking behavior in the rat. Behav Neurosci. 1998; 112:678-694. [PubMed: 9676983]

53. Tordoff MG, Friedman MI. Hepatic-portal glucose infusions decrease food intake and increase food preference. Am J Physiol. 1986; 251:R192-R196. [PubMed: 3728707]

54. Tsurugizawa T, Uematsu A, Nakamura E, Hasumura M, Hirota M, Uneyama H, Torii K. Mechanisms of neural response to gastrointestinal nutritive stimuli: The gut-brain axis. Gastroenterology. 2009; 137:262-273. [PubMed: 19248781]

55. Weingarten HP, Watson SD. Sham feeding as a procedure for assessing the influence of diet palatability on food intake. Physiol Behav. 1982; 28:401-407. [PubMed: 7079355] 
56. Yeomans MR. Flavour-nutrient learning in humans: An elusive phenomenon? Physiol Behav. 2012; 106:345-355. [PubMed: 22465846]

57. Yin TH, Tsai CT. Effects of glucose on feeding in relation to routes of entry in rats. J Comp Physiol Psychol. 1973; 85:258-264. [PubMed: 4756904]

58. Zukerman S, Ackroff K, Sclafani A. Rapid post-oral stimulation of intake and flavor conditioning by glucose and fat in the mouse. Am J Physiol Regul Integr Comp Physiol. 2011; 301:R1635R1647. [PubMed: 21975648] 


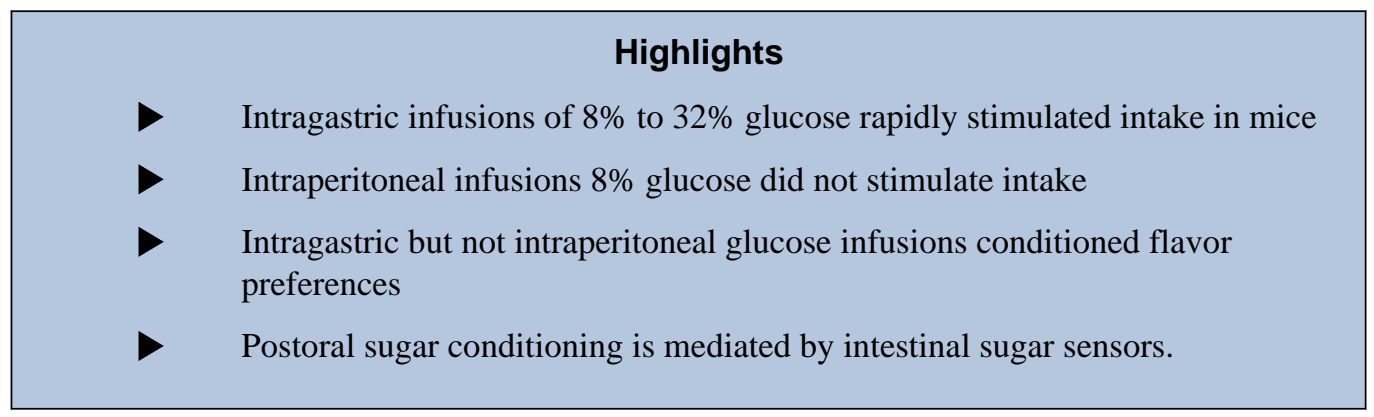



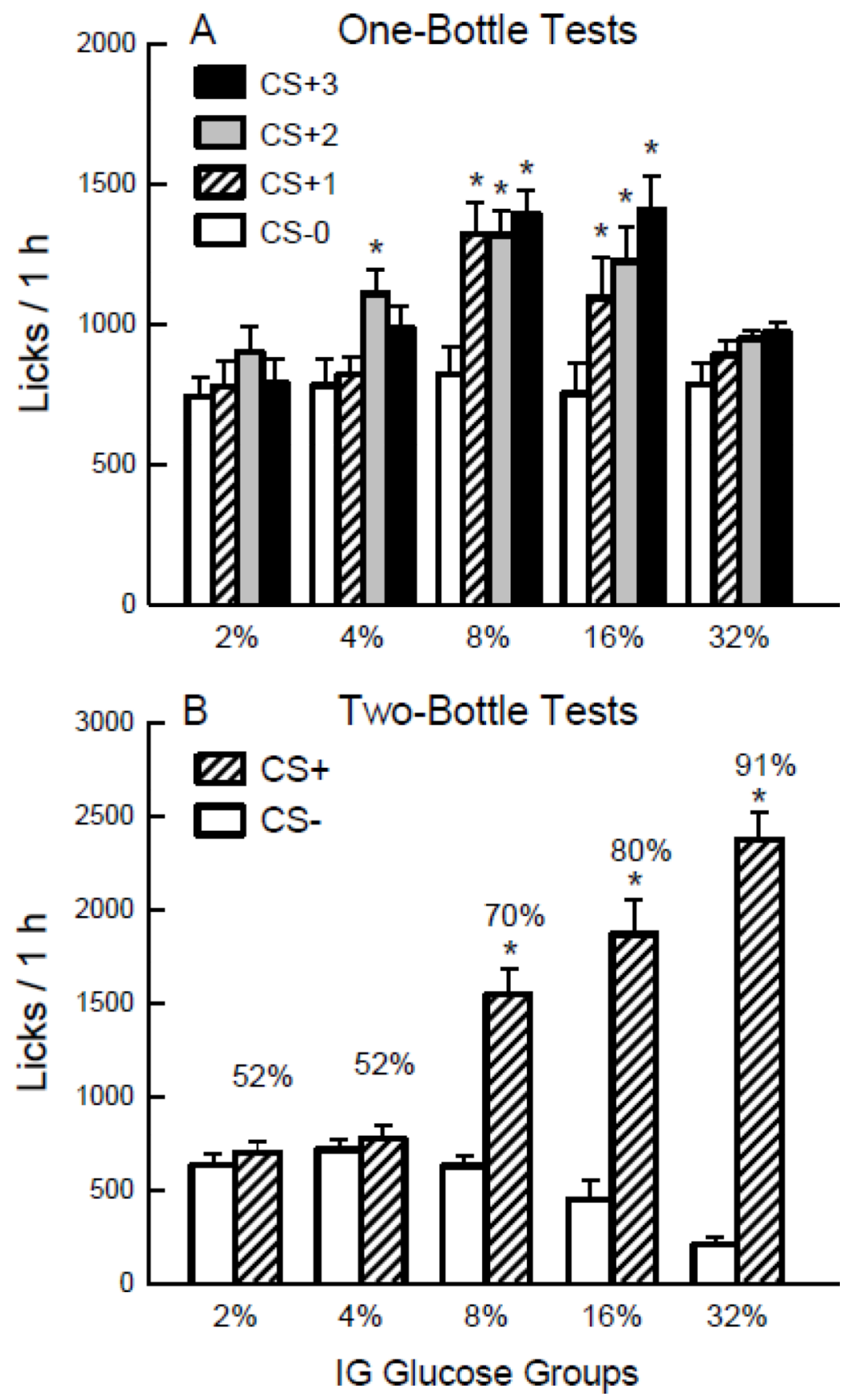

Figure 1.

A. Mean (+sem) 1-h total licks are plotted for one-bottle Tests $0-3$. The mice drank $(1 \mathrm{~h} /$ day) a CS- flavored saccharin solution paired with IG water infusions in Test 0 before being switched to a CS+ flavored saccharin solution paired with IG glucose self-infusions in Tests $1-3$. The five IG groups were infused with $2 \%, 4 \%, 8 \%, 16 \%$, and $32 \%$ glucose. B. Mean (+sem) 1-h licks are plotted for CS+ and CS- flavored saccharin solutions during the twobottle preference test for the $2 \%-32 \%$ IG glucose groups. CS+ and CS- intakes were not paired with IG infusions during test. Number atop bar represents mean percent preference for the CS+ solution. Significant differences $(\mathrm{P}<0.05)$ between Test 0 vs. Tests $1-3$ licks and between CS+ vs. CS- licks are indicated by an asterisk. 

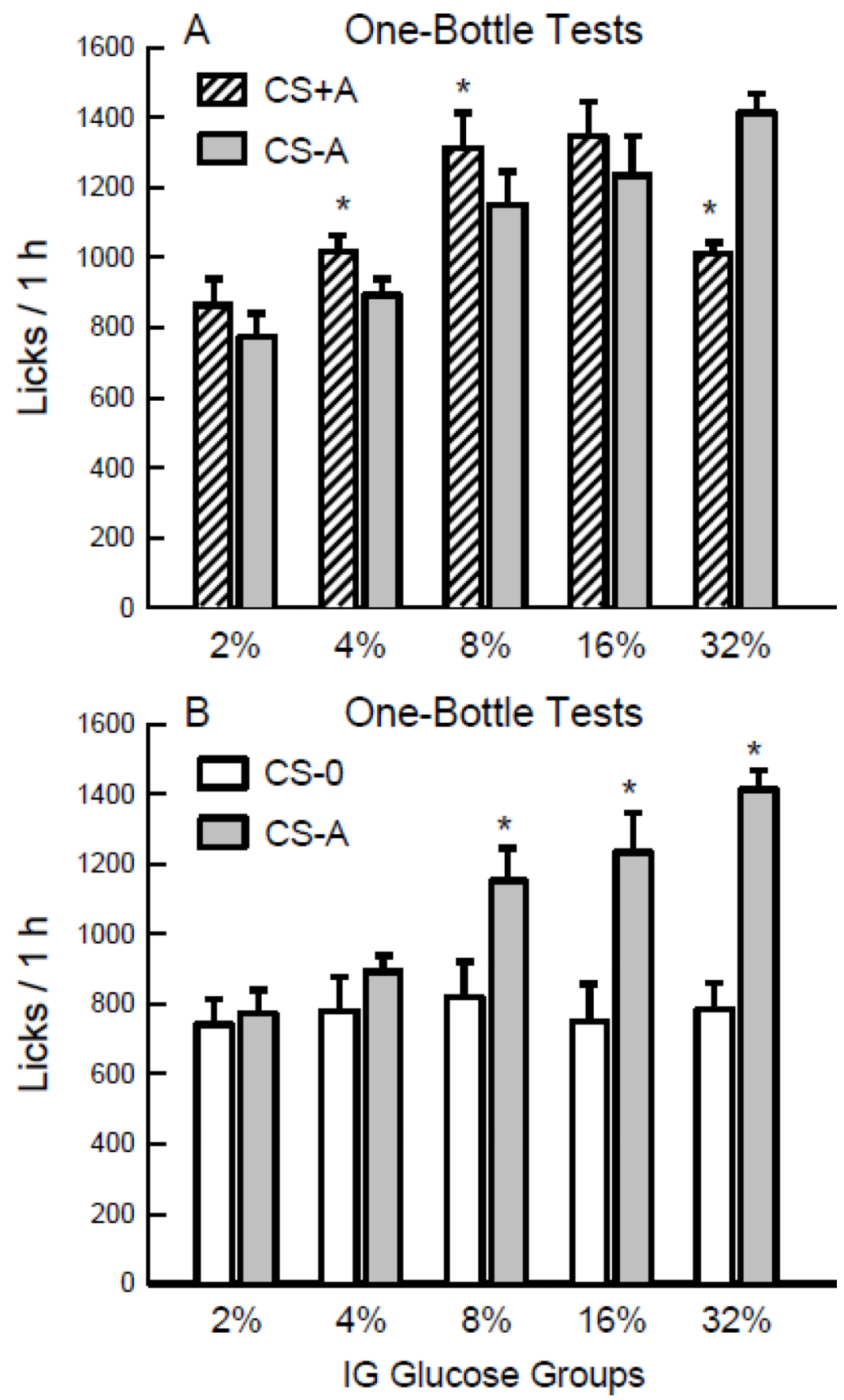

Figure 2.

A. Mean (+sem) 1-h total licks are plotted for the CS- and CS+ alternating (A) sessions following Tests 0 to 3 . The mice self-infused water during the CS-A sessions and $2 \%-32 \%$ glucose during the CS+A sessions. B. Mean (+sem) 1-h total licks are plotted for CS-0 Test and CS-A Test before and after CS+ Tests $1-3$. The mice were infused with water during these tests. Significant differences $(\mathrm{P}<0.05)$ between $\mathrm{CS}-\mathrm{A}$ and $\mathrm{CS}+\mathrm{A}$ and between $\mathrm{CS}-0$ and CS-A 1-h licks are indicated by an asterisk. 
A IG 2\% Glucose

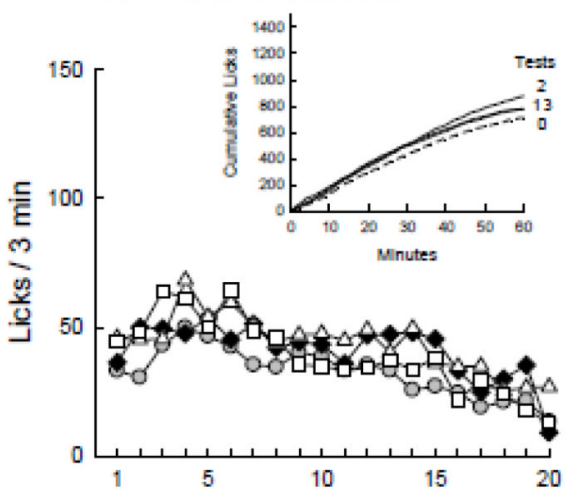

B IG 4\% Glucose

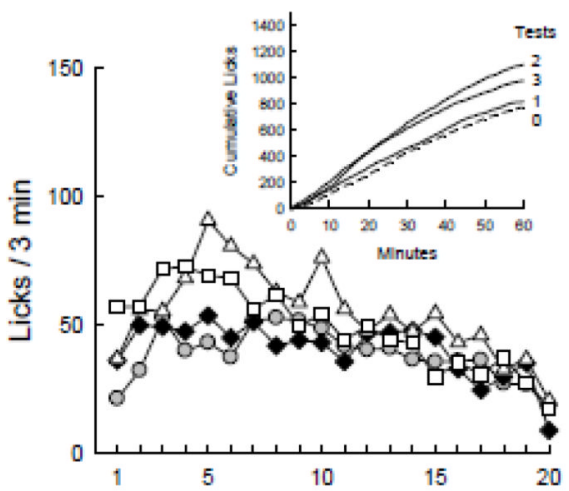

C IG $8 \%$ Glucose

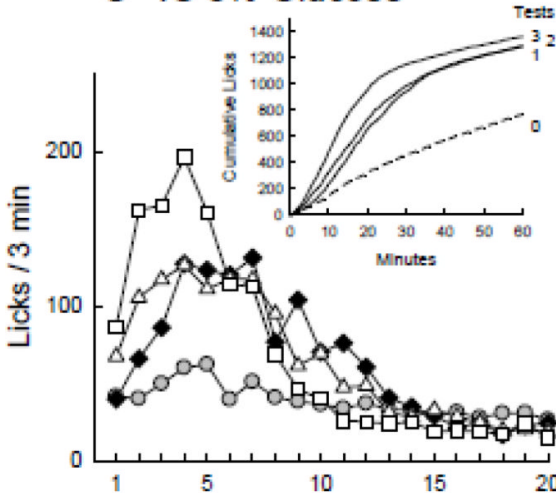

D IG $16 \%$ Glucose

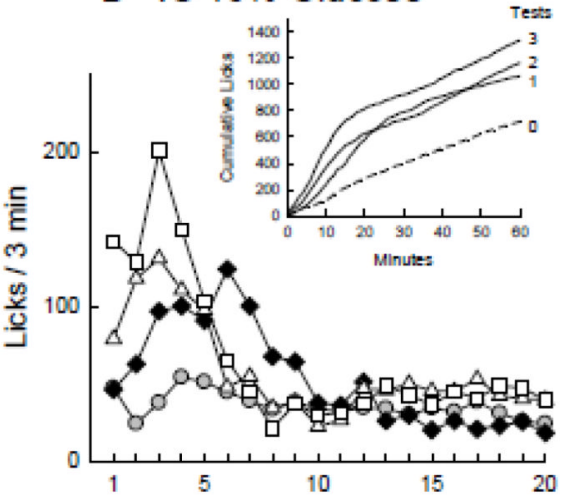

E IG $32 \%$ Glucose

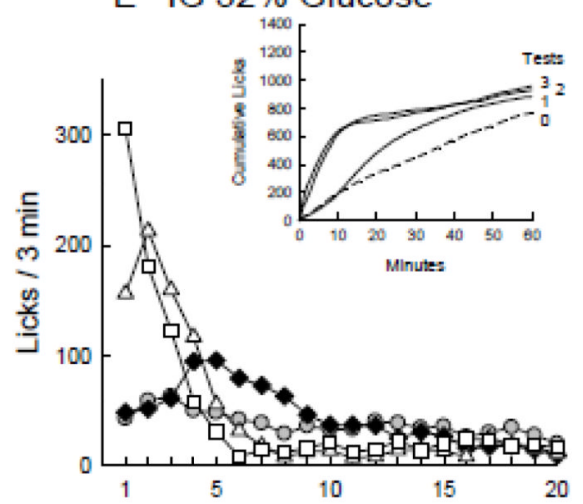

F IP 8\% Glucose

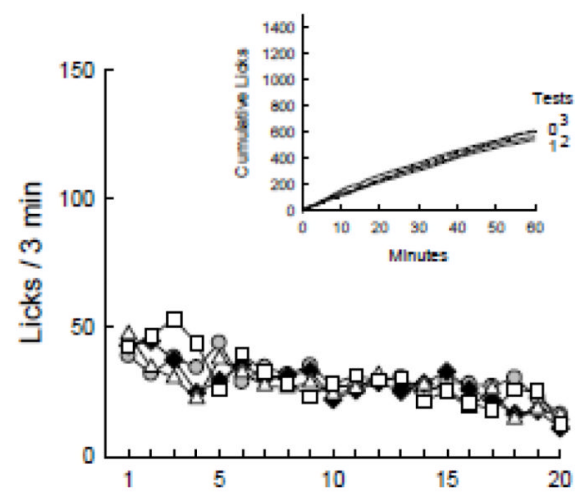

\section{3-min Bins}

CS- Test 00

CS+ Tests 1

$2 \triangle$

Figure 3.

Licks per 3-min bin are plotted for Test 0 with CS- flavored saccharin solution paired with IG water self-infusions, and for Tests $1-3$ with CS+ flavored saccharin solution paired with IG glucose self-infusions. Graph insets plots cumulative lick curves for Tests $0-3$. A. 2\% IG glucose group. Analysis of the 3-min data revealed no significant among between Tests 0-3. Overall, CS licks declined ( $\mathrm{P}<0.01)$ over bins 1 to 20 . B. 4\% IG glucose group. The mice licked more $(\mathrm{P}<0.05)$ for $\mathrm{CS}+$ in bin 5 of Test 2 than for CS- in Test 0. C. $8 \%$ IG glucose group. The mice licked more $(\mathrm{P}<0.05)$ for $\mathrm{CS}+$ in bins $3-11,2-8$, and 1-7 in Tests 1 to 3 , respectively, than for $\mathrm{CS}-$ in Test $0 . \mathrm{D} .16 \%$ group. The $16 \%$ group licked more $(\mathrm{P}<0.05)$ for CS+ in bins 2-8, 2-5, and 1-5 in Tests 1 to 3, respectively, than for CS- in Test 0 . E. 
$32 \%$ IG glucose group. The mice licked more $(\mathrm{P}<0.05)$ for $\mathrm{CS}+$ in bins $4-8,1-4$, and $1-3$ in Tests 1 to 3, respectively, than for CS- in Test 0 . F. IP $8 \%$ glucose group. The mice did not differ in their 3-min bin licks in Tests 0 to 3. Overall, CS licks declined $(\mathrm{P}<0.01)$ over bins 1 to 20 . 


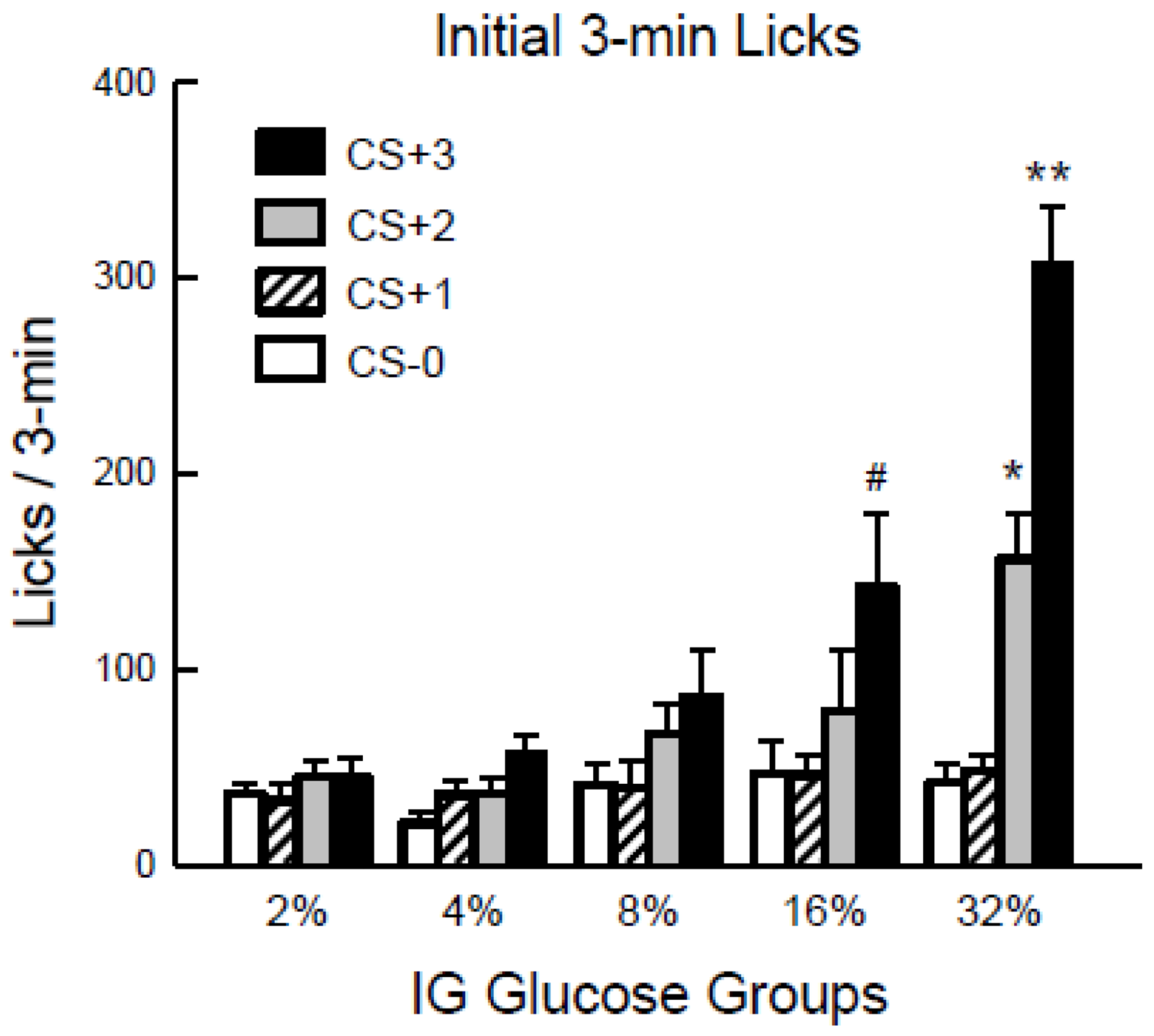

Figure 4.

Mean (+sem) licks in the first 3-min bins of CS- Test 0 and CS+ Tests 1 to 3 for the $2 \%$ to $32 \%$ IG groups. The number (\#) sign indicates that the $16 \%$ group licked more for CS+ in Test 3 than in Test 1 or for CS- in Test 0 . The asterisk indicates that the 32\% group licked more CS+ in Test 2 than in Test 1 or for CS- in Test 0 . The double asterisk indicates that the $32 \%$ group licked more for CS+ in Test 3 than for the CS+ or CS- in Tests 0 to 2. 

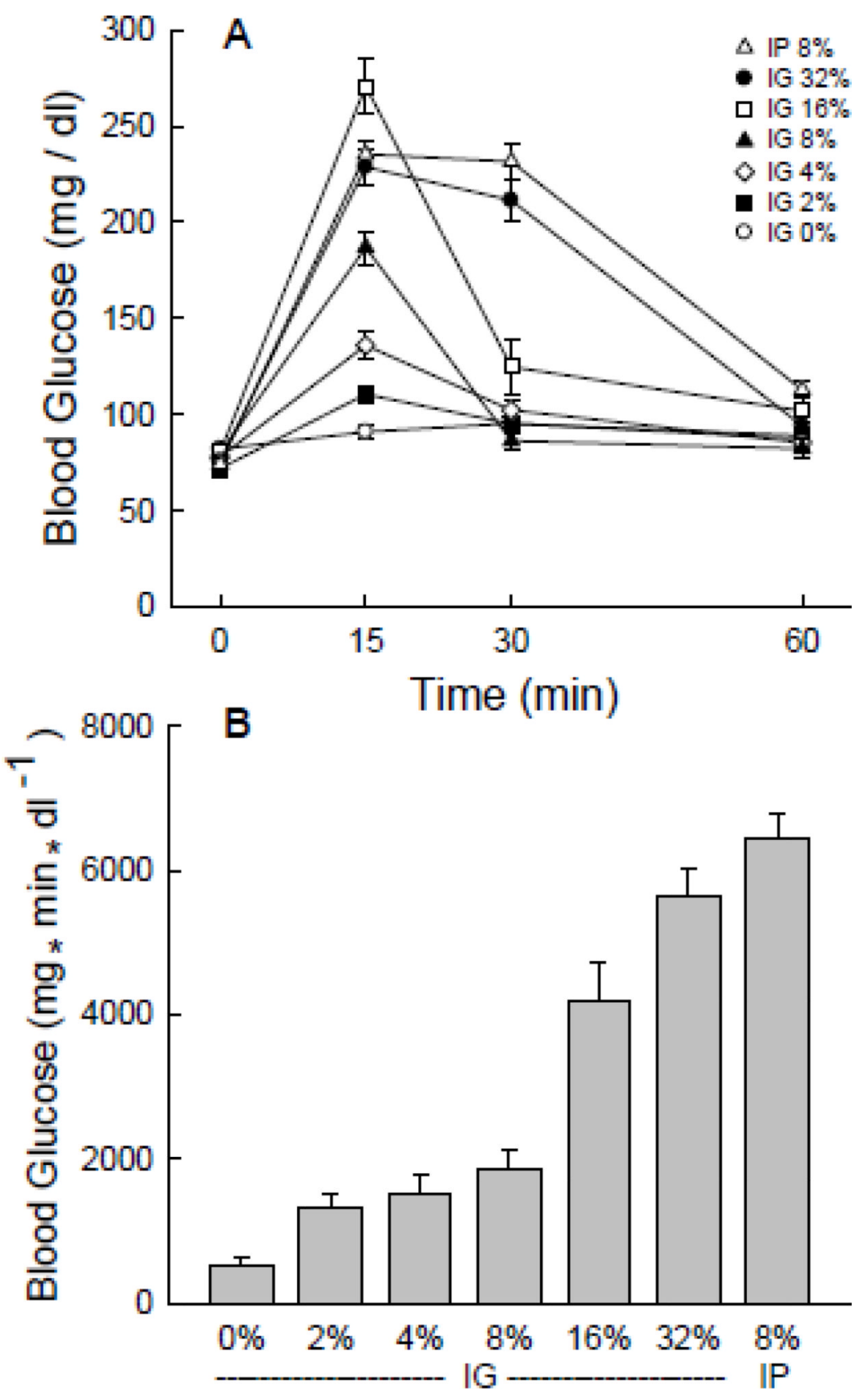

Groups

Figure 5.

A. Mean ( \pm sem) blood glucose at 0 and 15,30 and 60 min after a $0.6 \mathrm{ml}$ glucose infusion in IG $2 \%$ to $32 \%$ groups and IP $8 \%$ glucose group. B. Incremental blood glucose area under the curve after a $0.6 \mathrm{ml}$ IG or IP glucose infusion glucose or IG water infusion in IG $2 \%$ to $32 \%$ groups and IP $8 \%$ glucose group. The IG $0 \%$ group was infused with water. 


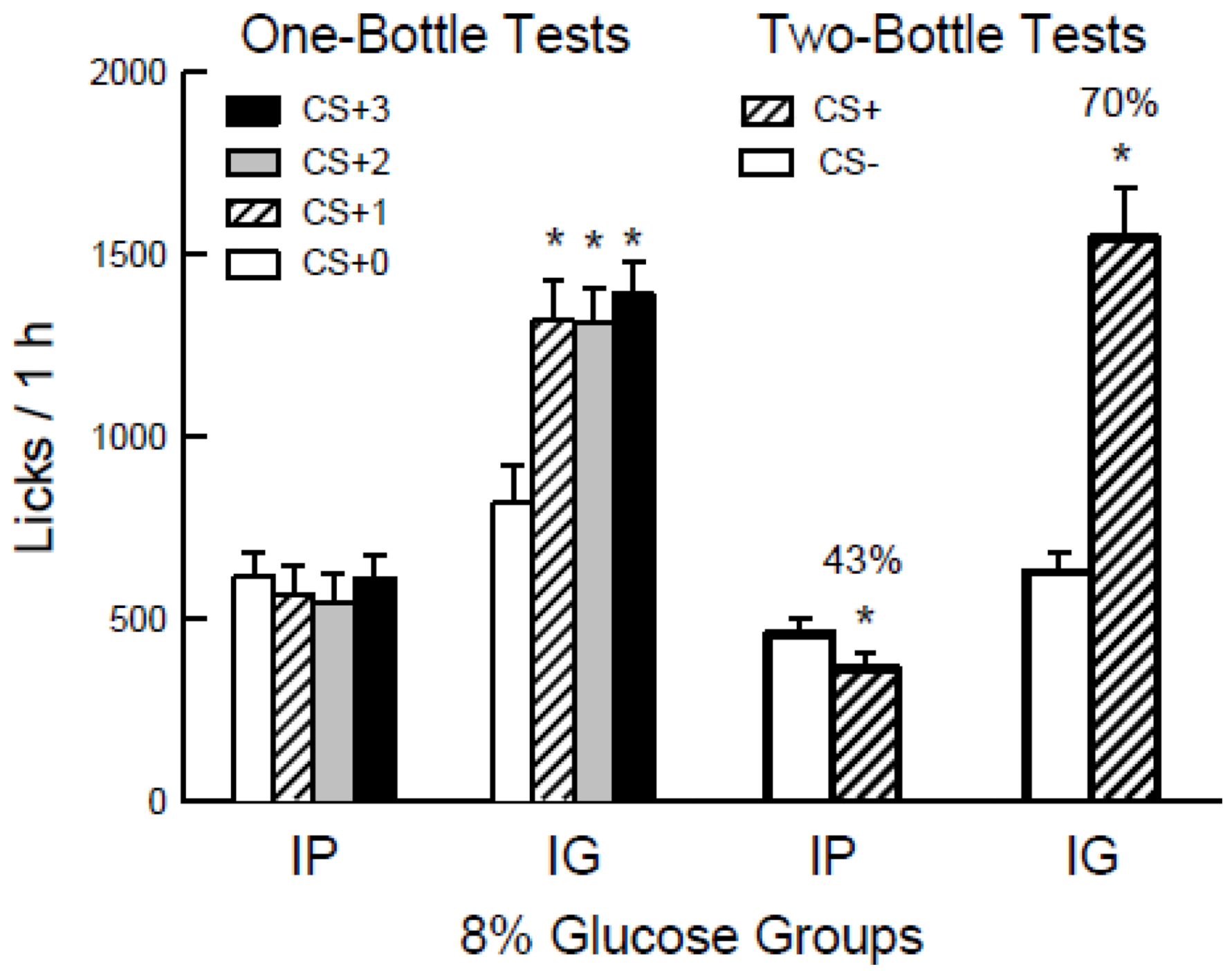

Figure 6.

A. Mean (+sem) 1-h total licks are plotted for one-bottle Tests $0-3$. The IP mice drank $(1 \mathrm{~h} /$ day) a CS- flavored saccharin solution paired with IG saline infusions in Test 0 before being switched to a CS+ flavored saccharin solution paired with IP $8 \%$ glucose self-infusions in Tests 1 - 3. The IG mice from Experiment 1 drank ( $1 \mathrm{~h} /$ day) a CS- flavored saccharin solution paired with IG water infusions in Test 0 before being switched to a CS+ flavored saccharin solution paired with IG $8 \%$ glucose self-infusions in Tests $1-3$. B. Mean (+sem) 1-h licks are plotted for CS+ and CS- flavored saccharin solutions during the two-bottle preference test for the IP and IG $8 \%$ glucose groups. CS+ and CS- intakes were not paired with infusions during test. Number atop bar represents mean percent preference for the CS+ solution. Significant differences $(\mathrm{P}<0.05)$ between Tests 0 vs. Tests $1-3$ licks and between CS+ vs. CS- licks are indicated by an asterisk. 